\title{
Energia Metabolizável e Relação Energia:Proteína Bruta nas Fases Pré-Inicial e Inicial de Frangos de Corte
}

\author{
Adriana Helena Nascimento ${ }^{1}$, José Humberto Vilar da Silva ${ }^{2}$, Luiz Fernando Teixeira Albino ${ }^{3}$, \\ Richard Cezar Runho4, Paulo Cezar Pozza ${ }^{5}$
}

\begin{abstract}
RESUMO - O trabalho foi realizado para avaliar o efeito da energia e da relação energia: proteína da ração sobre o desempenho e qualidade da carcaça de frangos de corte nas fases pré-inicial e inicial. Foram utilizados 900 pintos de corte, com peso médio de 41 g, distribuídos ao acaso em 45 boxes, em esquema fatorial 3 x 3, sendo três níveis de EMAn (2.850; 3.000 e 3.150 kcal) e três relações EM: PB (125; 136,9 e 151,5 kcal/\%PB), resultando em nove tratamentos com cinco repetições de 20 aves. De 1 a 7 dias, a melhor conversão alimentar (CA) foi obtida com 3.150 kcal EM e relação EM: PB de 125 (25,2 \%PB). No período de 1 a 21 dias, a redução da relação EM: PB (aumento da PB) em todos os níveis de EM melhorou o ganho de peso (GP) e a CA. As aves não ajustaram claramente o consumo pela densidade energética da ração. Rações com relação EM: PB de 136,9 (21,91\% PB) e EM de 3.000 kcal atenderam às exigências de frangos de corte para ótimo crescimento na fase inicial, enquanto a relação 151,5 foi inadequada. A redução da relação EM: PB diminuiu a gordura abdominal e melhorou a qualidade da carcaça de frangos de corte na fase inicial.
\end{abstract}

Palavras-chave: desempenho, gordura abdominal, qualidade da carcaça

\section{Metabolizable Energy and Energy:Protein Ratio for Male Broiler Chicks to Pre-Starter and Starter Phases}

\begin{abstract}
This work was undertaken to evaluate of dietary energy and energy: crude protein ratio on performance and carcass quality of broiler chicks in the pre-starter and starter phases. Were used 900 one day old male broiler chicks, weight of $41 \mathrm{~g}$, allotted in a completely randomized design in 45 boxes, in factorial 3 X 3, with three ME levels (2,850; 3,000 and 3,150 kcal) and three ME: CP ratio (125.0, 136.9 and $151.5 \mathrm{kcal} / \% \mathrm{CP})$, resulting in nine treatments with five replicates of 20 birds. From 1 to 7 days, better feed conversion ratio was obtained with 3,150 kcal ME and ME: CP ratio of 125 (25,2\% CP). From 1 to 21 days, when ME: CP ratio decreased (increase of CP), within of ME levels, improved weight gain and feed conversion ratio. The broiler chicks feed intake was not clearing affect by dietary ME levels. Diets with 136.9 ME: CP ratio (21.91\% CP) and 3,000 kcal ME attend the broilers requirements for optimum growth in start phase, while 151.5 ME: CP ratio was inadequate. The reduction of ME: CP ratio decrease lipid and improves poultry carcass quality in start phase.
\end{abstract}

Key Words: abdominal fat, carcass quality, performance

\section{Introdução}

O balanceamento de rações para maximizar o desempenho e a qualidade da carcaça em frangos de corte ainda é uma decisão difícil para a indústria avícola, em virtude das implicações existentes quanto às respostas e suas conseqüências sobre o custo de produção das aves.

A preocupação dos consumidores com o teor de gordura nas carnes vem aumentando a pressão pública sobre as instituições de pesquisas, indústrias avícolas, de processamento e comercialização de carnes para o desenvolvimento de estratégias que reduzam a adiposidade da carcaça de frangos de corte (Silva et al., 2003). Atualmente, o objetivo da produção de frangos de corte não é obter apenas ótimo peso de abate associado à melhor conversão alimentar, mas produzir também carcaças com alta proporção de tecido magro.

Vários fatores podem ser listados como responsáveis pelo aumento ou redução da concentração de lipídeos na carcaça de frangos, destacando-se o

\footnotetext{
${ }^{1}$ Ajinomoto Biolatina - São Paulo - SP (adriana_nascimento@bil.ajinomoto.com).

${ }^{2}$ Departamento de Agropecuária/CFT/UFPB/Campus IV - Bananeiras/PB. CEP: 58220-000 (jvilar@cft.ufpb.br).

${ }^{3}$ Departamento de Zootecnia/UFV - Viçosa/MG. CEP. 36.570-000 (lalbino@ufv.br).

${ }^{4}$ Agroceres.

${ }^{5}$ Universidade Estadual do Paraná - Campus de Marechal Cândido Rondon.
} 
genótipo, a idade, a temperatura ambiente e a relação caloria: proteína. Particularmente, os níveis de proteína e de energia das rações estão diretamente relacionados à deposição de tecido magro na carcaça de frangos de corte (Jackson et al., 1982; Emmans, 1995; Bartov \& Plavnik, 1998, Silva et al., 2001; Silva et al., 2003), em razão da quantidade de gordura depositada ser proporcional à quantidade de energia disponível para a síntese (Leeson, 1995); se o conteúdo de energia da ração é diminuído em relação ao de proteína, o teor de lipídio na carcaça deve cair (Rosebrough et al., 1990; Round, 1992; Holsheimer \& Rurnski, 1993; Bertechini et al., 1991; Emmans, 1995).

A influência negativa do aumento da relação energia: proteína sobre a qualidade da carcaça já na fase de 1 a 21 dias foi demonstrada por Zanusso (1998). O autor observou que, quando a relação EM: PB foi elevada de 128 para 132; 135; 138 e 142 (22,19\% PB e 2.850; 2.925; 3.000; 3.075 e 3.150 kcal EM), houve crescimento linear do ganho de peso, de gordura abdominal, proteína e gordura na carcaça das aves. Entretanto, o conteúdo de proteína da carcaça cresceu menos (9\%) em comparação com o crescimento de lipídeo (13\%). Segundo Macleod (1991), com excesso de energia na ração em relação à proteína, os frangos de corte respondem com aumento na taxa de deposição de gordura, sem alterarem a dissipação de energia, na forma de calor.

Portanto, a alta quantidade de gordura depositada na carcaça de frangos de corte é um sério problema da avicultura moderna, que afeta tanto o rendimento dos cortes nobres quanto à qualidade da carcaça para o consumo. Várias relações energia:proteína têm sido testadas na formulação de rações e, geralmente, são acompanhadas de mudanças na composição corporal, especialmente na deposição de proteína e de gordura (Silva et al., 2003), pois, ao se estabelecer a relação energia:nutrientes da dieta, o consumo de proteína (aminoácidos) e de outros nutrientes pode ser afetado (Penz Jr. et al., 1999).

Este trabalho teve o objetivo de avaliar o efeito da energia e da relação energia:proteína da ração sobre o desempenho e a qualidade da carcaça de frangos de corte de 1 a 7 e de 1 a 21 dias de idade.

\section{Material e Métodos}

O experimento foi realizado na Seção de Avicultura do Departamento de Zootecnia da Universidade Federal de Viçosa. As temperaturas médias registradas durante o período experimental foram de $34^{\circ} \mathrm{C}$ (máxima) ede $26^{\circ} \mathrm{C}$ (mínima), obtidasutilizando-se dois termômetros localizados no centro do galpão.

O delineamento experimental foi o inteiramente ao acaso em esquema fatorial $3 \times 3$, sendo três níveis de energia (2.850; 3.000 e 3.150 kcal) e três relações EM: PB (125; 136,9 e 151,5 kcal EM/\%PB), totalizando nove tratamentos, cada um com cinco repetições de 20 aves.

Foram utilizados 900 pintos de corte, Avian Farms, vacinados contra Bouba aviária e Marek, com peso médio de $41 \mathrm{~g}$, distribuídos ao acaso em 45 boxes. As aves foram criadas por um período de 1 a 21 dias de idade, sob programa de luz contínua (24 horas), com luz natural e luz artificial, durante todo o período experimental.

As rações experimentais (Tabela 1) foram formuladas de acordo com as exigências nutricionais de frangos de corte na fase de 1 a 21 dias, segundo Rostagno et al. (1996), tendo como dieta basal a ração contendo 21,91\% PB, 3.000 kcal de EM e relação EM: PB de 136,9. A composição dos alimentos encontra-se na Tabela 2.

As variáveis estudadas foram ganho de peso (GP), consumo de ração (CR) e conversão alimentar (CA), nos períodos de 1 a 7, 8 a 21 e 1 a 21 dias de idade. Aos 21 dias de idade, foram selecionadas e abatidas quatro aves, com aproximadamente $5 \%$ do peso vivo médio de cada parcela. A porcentagem de gordura abdominal (\%GA), composta do tecido adiposo em volta da bursa de Fabricius, proventrículo, moela e cloaca, foi avaliada em relação ao peso da carcaça limpa.

Para as análises de composição química, as carcaças inteiras (com pés e cabeça) de duas aves foram moídas em aparelho “cutter” de 30 HP e 1775 rpm e, após homogeneização, amostras compostas foram retiradas, pré-secas em estufa com ventilação forçada a $55^{\circ} \mathrm{C}$, por 72 horas. Em seguida, foi realizado o prédesengorduramento, pelo método a quente no extrator "Soxhlet" durante quatro horas. Finalmente, as amostras foram moídas, acondicionadas em vidros e armazenadas para as avaliações de matéria seca, lipídio e proteína na carcaça.

As análises estatísticas foram realizadas pelo programa SAEG (UFV, 1982). No caso de interação significativa $(\mathrm{P}<0,05)$, o efeito de um fator foi estudado dentro do outro e, na ausência de interações significativas, as médias de cada fator principal foram comparadas entre si. Os dados foram analisados pelo 


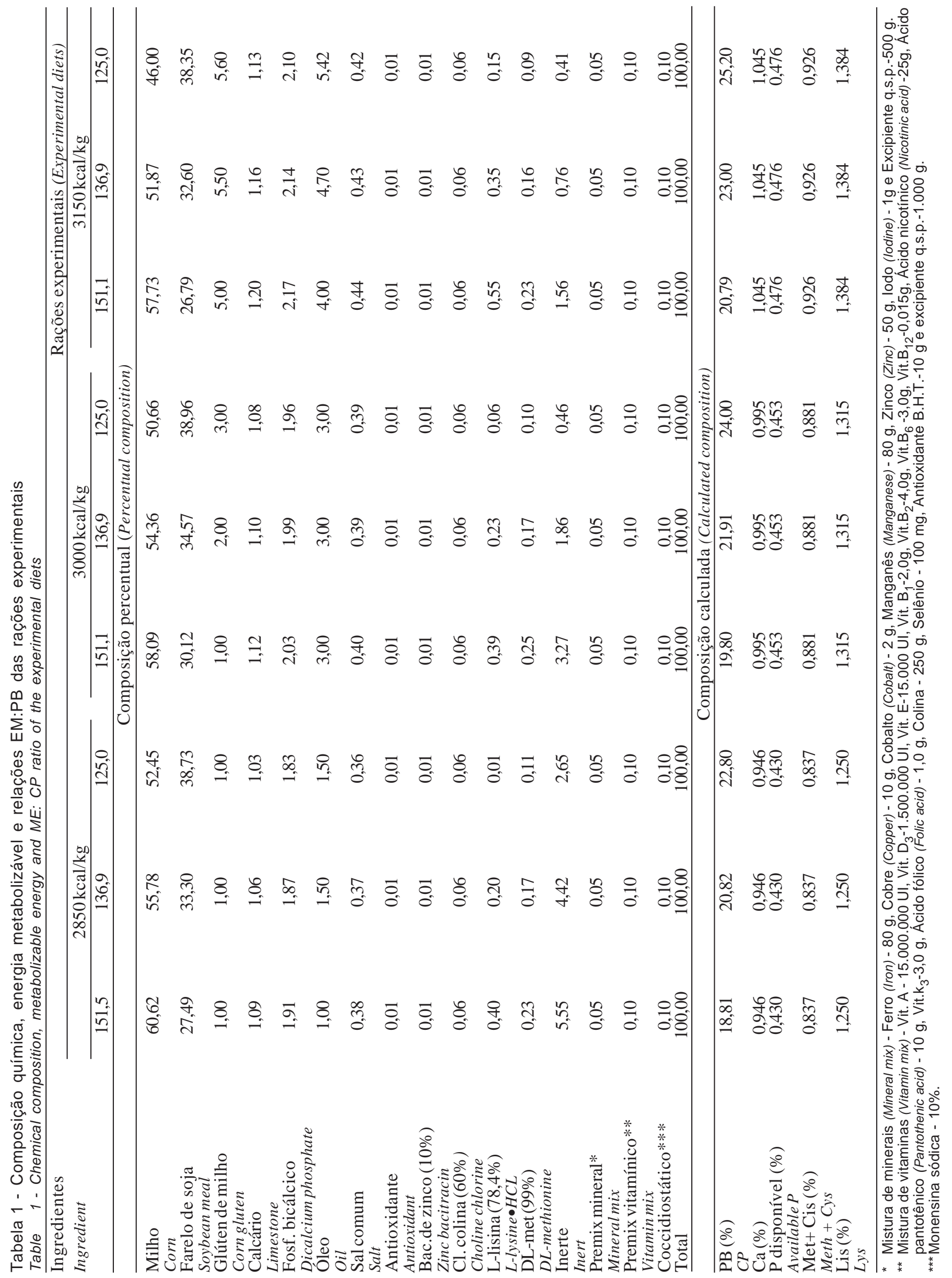


teste F e Student-Newman Keuls $(\mathrm{P}<0,05)$, de acordo com o seguinte modelo estatístico:

$$
\mathrm{Y}_{\mathrm{ijk}}=\mu+\mathrm{E}_{\mathrm{i}}+\mathrm{R}_{\mathrm{j}}+\mathrm{R}^{*} \mathrm{E}_{(\mathrm{ij})}+\mathrm{e}_{\mathrm{ijk}}
$$

em que: $\mathrm{Y}_{\mathrm{ijk}}=$ variável observada na ${ }_{\mathrm{k}}$-ésima repetição, que recebeu o -ésimo nível de EM e a ${ }_{\mathrm{j}}$-ésima relação EM: PB; $\mu$ = média geral do experimento; $\mathrm{E}_{\mathrm{i}}=$ efeito do ${ }_{\mathrm{i}}$-ésimo nível de $\mathrm{EM}$ da ração, sendo $_{\mathrm{i}}=2.850$, 3.000 e $3.150 \mathrm{kcal} / \mathrm{kg}$ de ração; $\mathrm{R}_{\mathrm{j}}=$ efeito da -ésima relação EM: $P B$, sendo = 125,0; 136,9 e 151,5; R* $\mathrm{E}_{(\mathrm{ij})}=$ efeito da interação do -ésimo nível de EM com a -ésima relação EM: PB da ração; $\mathrm{e}_{\mathrm{ijk}}=$ erro aleatório associado a cada observação.

\section{Resultados e Discussão}

Os resultados de desempenho dos frangos de corte de 1 a 7 dias, 8 a 21 e de 1 a 21 dias são apresentados nas Tabelas 3, 4 e 5.

Não houve interação $(P>0,05)$ dos níveis de energia com a relação EM: PB sobre o consumo de ração das aves nos períodos de 8 a 21 e de 1 a 21 dias (Tabela 3). O nível de EM como efeito principal não também afetou o consumo $(\mathrm{P}>0,05)$, mas a relação EM: PB de 136,9 proporcionou maior consumo nestes períodos $(\mathrm{P}<0,05)$. As reduções do consumo nas relações EM:PB de 125,0 e 151,5, foram causadas, provavelmente, pelo desequilíbrio na concentração entre proteína (aminoácidos) e energia da ração. Resultado semelhante foi observado por Silva et al. (2003) em frangos de corte de 22 a 42 dias de idade.

O consumo de ração das aves não foi afetado pelo aumento do nível de energia metabolizável $(\mathrm{P}>0,05)$. Este resultado corrobora os de Benício (1995), que também trabalhou com pintos de 1 a 21 dias de idade. Os mecanismos de regulação do consumo de alimento pelos animais ainda não estão bem esclarecidos e a hipótese de que frangos de corte consomem alimento para satisfazer as necessidades energéticas não se confirmou em frangos de corte na fase inicial e, provavelmente, somente deve ocorrer na fase adulta.

Scott et al. (1982) afirmaram que os frangos de corte na fase inicial têm metabolismo acelerado, não sendo possível controlar bem o consumo de ração pelo nível de energia da dieta. Segundo Maiorka et al. (1997), o consumo de ração só deve ser adequadamente regulado pela energia após a terceira semana de idade, o que pode estar relacionado à possibilidade de as aves ainda não digerirem eficientemente os lipídios. Silva et al. (2001) também não detectaram declínio no consumo de ração em frangos de corte de 22 a 42 dias de idade, quando o nível de EM da ração passou de 2.900 para 3.100 e 3.300 kcal de EM.

Na fase pré-inicial, a melhor conversão alimentar $(\mathrm{P}<0,05)$ foi constatada no nível de $3.150 \mathrm{kcal}$ de EM e na relação EM: PB de 125 como efeitos principais (Tabela 3). Ao contrário, Stringhini et al. (2001) não encontraram nenhum efeito da relação EM: PB de 115, 125, 135 e 145 sobre a conversão alimentar na primeira semana de vida de pintinhos de corte. A hipótese de que os pintinhos exigem mais EM e PB na ração nessa fase deve ser explicada pela menor capacidade digestiva (Batal \& Parsons, 2002) e rápida taxa de crescimento das aves.

Os piores resultados de conversão alimentar nos períodos pré-inicial e de 8 a 21 dias foram detectados no nível de EM de 2.850 kcal e nas relações EM:PB de 136,9 e 151,5 (Tabela 3), enquanto as melhores conversões foram verificadas com $3.150 \mathrm{kcal}$ de EM e relação EM: PB de $125(\mathrm{P}<0,05)$.

Durante o período de 1 a 7 dias, o consumo sofreu efeito de interação $(P<0,05)$ entre a EM com a relação EM: PB (Tabela 4). Dentro do nível de EM de 2.850 kcal, observou-se que a relação EM:PB de 125 afetou o consumo (142 g), enquanto dentro dos níveis

Tabela 2 - Composição química dos alimentos Table 2 - Feedstuffs chemical composition

\begin{tabular}{|c|c|c|c|}
\hline \multirow[b]{2}{*}{$\begin{array}{l}\text { Nutriente } \\
\text { Nutrient }\end{array}$} & \multicolumn{3}{|c|}{$\begin{array}{l}\text { Alimentos } \\
\text { Feedstuffs }\end{array}$} \\
\hline & $\begin{array}{l}\text { Milho } \\
\text { Corn }\end{array}$ & $\begin{array}{c}\text { Farelo } \\
\text { de soja } \\
\text { Soybean } \\
\text { meal }\end{array}$ & $\begin{array}{l}\text { Glúten } \\
\text { de milho } \\
\text { Corn } \\
\text { gluten }\end{array}$ \\
\hline $\begin{array}{l}\mathrm{PB}(\%)^{1} \\
C P^{1}\end{array}$ & 7,60 & 46,12 & 60,00 \\
\hline $\begin{array}{l}\operatorname{EM}(\mathrm{kcal} / \mathrm{kg})^{2} \\
M E^{2}\end{array}$ & 3.416 & 2.283 & 3.624 \\
\hline $\begin{array}{l}\mathrm{Ca}(\%)^{2} \\
\mathrm{Ca}^{2}\end{array}$ & 0,02 & 0,36 & 0,06 \\
\hline $\begin{array}{l}\text { P disp. }(\%)^{2} \\
P \text { available }\end{array}$ & 0,09 & 0,18 & 0,12 \\
\hline $\begin{array}{l}\text { Met }+ \text { Cis }(\%)^{2} \\
M e t+\text { Cis }^{2}\end{array}$ & 0,35 & 1,34 & 2,70 \\
\hline $\begin{array}{l}\operatorname{Lis}(\%)^{2} \\
\operatorname{Lys}^{2}\end{array}$ & 0,23 & 2,87 & 1,00 \\
\hline
\end{tabular}


de 2.850 e 3.000 kcal EM, a relação 136,9 proporcionou melhor consumo $(\mathrm{P}<0,05)$. Avaliando o efeito dos níveis de energia dentro das diferentes relações EM: PB, observou-se que, dentro da relação EM: PB de 136,9, o nível de EM de 3.000 kcal melhorou o consumo de ração em relação aos níveis de 2.850 e 3.150 kcal $(\mathrm{P}<0,05)$.

No período de 1 a 21 dias, houve interação entre a EM e a relação EM:PB sobre o ganho de peso e a conversão alimentar $(\mathrm{P}<0,05)$.
Para o ganho de peso das aves, houve efeito de interação entre o nível de energia metabolizável (EM) com a relação EM:PB da ração nos períodos de 8 a 21 e de 1 a 21 dias $(P<0,05)$. As diferentes relações EM: $\mathrm{PB}$, dentro da densidade de 2.850 kcal de EM, não tiveram efeito sobre o ganho de peso das aves, mas afetaram $(\mathrm{P}<0,05)$ quando as rações continham 3.000 kcal de EM, sendo o melhor resultado obtido com a ração contendo relação EM:PB de 136,9 (21,91 \%PB). Quando o nível de EM passou para 3.150 kcal, não

Tabela 3 - Efeito da energia e da relação EM: PB sobre ganho de peso (GP), consumo de ração (CR) e conversão alimentar (CA) de frangos de corte de 1 a 7,8 a 21 e 1 a 21 dias de idade

Table 3 - Effects of energy and ME: CP ratio on weight gain (WG), feed intake (FI) and feed conversion ratio (FC) of male broiler chicks from 1 to 7,8 to 21 and 1 to 21 days of age

\begin{tabular}{|c|c|c|c|c|c|}
\hline \multirow{3}{*}{$\begin{array}{l}\text { EM } \\
M E \\
\end{array}$} & \multicolumn{2}{|c|}{$\begin{array}{l}\text { 1-7 dias } \\
1-7 \text { days }\end{array}$} & \multicolumn{2}{|c|}{$\begin{array}{l}\text { 8-21 dias } \\
\text { 8-21 days }\end{array}$} & \multirow{2}{*}{$\begin{array}{c}\text { 1-21 dias } \\
\text { 1-21 days } \\
\text { CR }(\mathrm{g})\end{array}$} \\
\hline & GP(g) & CA (kg/kg) & CR (g) & CA (kg/kg) & \\
\hline & $W G$ & FC & FI & $F C$ & FI \\
\hline 2.850 & 104 & $1,379^{a}$ & 847 & $1,585^{\mathrm{a}}$ & 995 \\
\hline 3.000 & 110 & $1,323^{b}$ & 862 & $1,481^{\mathrm{b}}$ & 1010 \\
\hline 3.150 & 110 & $1,266^{c}$ & 839 & $1,410^{c}$ & 981 \\
\hline \multicolumn{6}{|l|}{$\begin{array}{l}\mathrm{EM}: \mathrm{PB} \\
(M E: C P)\end{array}$} \\
\hline 125,0 & 106 & $1,285^{\mathrm{B}}$ & $830^{\mathrm{B}}$ & $1,452^{\mathrm{B}}$ & $972^{\mathrm{B}}$ \\
\hline 136,9 & 111 & $1,334^{\mathrm{A}}$ & $872^{\mathrm{A}}$ & $1,496^{\mathrm{A}}$ & $1023^{\mathrm{A}}$ \\
\hline 151,5 & 109 & $1,349^{\mathrm{A}}$ & $846^{\mathrm{B}}$ & $1,532^{\mathrm{A}}$ & $991^{\mathrm{B}}$ \\
\hline CV $(\%)$ & 6,99 & 3,29 & 3,82 & 3,54 & 3,42 \\
\hline
\end{tabular}

a,b,c Letras minúsculas comparam médias de energia pelo teste SNK $(P<0,05)$.

$a, b, c$ Small letters comparing means of energy by SNK test $(P<.05)$.

A,B Letras maiúsculas comparam médias das relações EM: PB pelo teste SNK $(P<0,05)$.

$A, B \quad$ Capital letters comparing means of ME: CP ratio by SNK test $(P<.05)$.

Tabela 4 - Efeito da energia e da relação EM:PB sobre consumo de ração (CR), ganho de peso (GP) e conversão alimentar (CA) de frangos de corte de 1 a 7, 8 a 21 e 1 a 21 dias de idade

Table 4 - Effects of energy and ME: CP ratio on feed intake (FI), weight gain (WG) and feed conversion ratio (FC) of male broiler chicks of 1 to 7,8 to 21 and 1 to 21 days of age

\begin{tabular}{|c|c|c|c|c|c|c|c|c|c|c|c|c|}
\hline \multirow{3}{*}{$\begin{array}{l}\text { EM:PB } \\
M E: C P\end{array}$} & \multicolumn{3}{|c|}{$\begin{array}{l}\text { 1-7 dias } \\
\text { 1-7 days }\end{array}$} & \multicolumn{3}{|c|}{$\begin{array}{l}\text { 8-21 dias } \\
\text { 8-21 days }\end{array}$} & \multicolumn{6}{|c|}{$\begin{array}{l}1-21 \text { dias } \\
1-21 \text { days }\end{array}$} \\
\hline & \multicolumn{3}{|c|}{$\begin{array}{c}\text { CR (g) } \\
\text { FI }\end{array}$} & \multicolumn{3}{|c|}{$\begin{array}{c}\mathrm{GP}(\mathrm{g}) \\
W G\end{array}$} & \multicolumn{3}{|c|}{$\begin{array}{c}\text { GP(g) } \\
W G\end{array}$} & \multicolumn{3}{|c|}{$\begin{array}{c}\mathrm{CA}(\mathrm{kg} / \mathrm{kg}) \\
F C\end{array}$} \\
\hline & 2.850 & 3.000 & 3.150 & 2.850 & 3.000 & 3.150 & 2.850 & 3.000 & 3.150 & 2.850 & 3.000 & 3.150 \\
\hline 125,0 & $142^{\mathrm{aB}}$ & $143^{\mathrm{aB}}$ & $140^{\mathrm{aA}}$ & $536^{\mathrm{bA}}$ & $563^{\mathrm{bB}}$ & $622^{\mathrm{aA}}$ & $636^{\mathrm{cA}}$ & $672^{\mathrm{bB}}$ & $730^{\mathrm{aA}}$ & $1,525^{\mathrm{aB}}$ & $1,455^{\mathrm{bA}}$ & $1,337^{\mathrm{cB}}$ \\
\hline 136,9 & $152^{\mathrm{bA}}$ & $160^{\mathrm{aA}}$ & $144^{\mathrm{cA}}$ & $548^{\mathrm{bA}}$ & $611^{\mathrm{aA}}$ & $596^{\mathrm{aA}}$ & $655^{\mathrm{bA}}$ & $724^{\mathrm{aA}}$ & $709^{\mathrm{aA}}$ & $1,522^{\mathrm{aB}}$ & $1,461^{\mathrm{bA}}$ & $1,367^{\mathrm{cB}}$ \\
\hline 151,5 & $148^{\mathrm{aAB}}$ & $\begin{array}{c}144^{\mathrm{aB}} \\
3,98\end{array}$ & $144^{\mathrm{aA}}$ & $520^{\mathrm{bA}}$ & $\begin{array}{c}569^{\mathrm{aB}} \\
3,61\end{array}$ & $569^{\mathrm{aB}}$ & $626^{\mathrm{bA}}$ & $\begin{array}{c}675^{\mathrm{aB}} \\
3,06\end{array}$ & $678^{\mathrm{aB}}$ & $1,582^{\mathrm{aA}}$ & $\begin{array}{c}1,475^{\mathrm{bA}} \\
1,58\end{array}$ & $1,444^{\mathrm{cA}}$ \\
\hline
\end{tabular}

a,b,c Letras minúsculas comparam as médias de energia dentro de cada relação EM: PB pelo teste $\operatorname{SNK}(P<0,05)$.

$a, b, c$ Small letters comparing means of energy within each ratio by SNK test $(P<.05)$.

A,B Letras maiúsculas comparam as médias das relações $\mathrm{EM}$ : PB dentro de cada valor de EM pelo teste de $\mathrm{SNK}(\mathrm{P}<0,05)$.

$A, B \quad$ Capital letters comparing means of ME: CP ratio within of each ME value by $S N K$ test $(P<.05)$. 
existiram diferenças no ganho de peso entre as aves alimentadas com rações contendo relações EM: PB de 125,0 e 136,9, que influenciaram ganho de peso superior ao das aves alimentadas na relação 151,5.

Os resultados do presente estudo corroboram aquele de Zanusso (1998), que observou melhor ganho de peso com relação EM:PB de 138, e sugerem maiores ganhos de peso em frangos de corte na fase inicial somente quando o nível de proteína estiver adequadamente equilibrado com o nível energético da ração; caso contrário, o desequilíbrio na relação EM:PB afeta o desempenho.

O maior ganho de peso (730g) foi constatado com $3.150 \mathrm{kcal}$ de EM e $25,2 \%$ de $\mathrm{PB}(\mathrm{P}<0,05)$. As aves que receberam a ração com $3.000 \mathrm{kcal}$ EM e 21,91\% PB tiveram ganho de peso semelhante (724 g). Segundo Pesti \& Fletcher (1993), para atingir máximo ganho de peso, os frangos alimentados com alta energia precisam de mais proteína na ração. Silva et al. (2003) também relataram que a exigência de proteína de frangos de corte elevou-se com o aumento da energia da ração.

Dentro do nível de EM de 2.850 e 3.150 kcal, as melhores conversões foram detectadas nas relações 125 e 136,9 $(\mathrm{P}<0,05)$ e as piores, na relação 151,5. Dentro do nível de $3.000 \mathrm{kcal}$, não houve diferenças $(\mathrm{P}>0,05)$ entre as três relações EM: PB (Tabela 4). Avaliando o efeito da densidade energética dentro de cada relação EM:PB, observou-se que o nível de 3.150 kcal influenciou melhor conversão $(\mathrm{P}<0,05)$ que os níveis de 2.850 e $3.000 \mathrm{kcal}$ EM, enquanto os piores resultados foram verificados quando a ração tinha $2.850 \mathrm{kcal}$ de EM.

Pode-se observar que a gordura abdominal das aves cresceu $(\mathrm{P}<0,05)$ com o aumento da EM da ração (Tabela 5), não havendo diferenças para aquelas com 3.000 e $3.150 \mathrm{kcal}$ de EM/kg. Por outro lado, maior porcentagem de gordura abdominal foi encontrada na relação 151,5 (menos PB na ração) e nenhuma diferença foi encontrada entre as relações 125 e 136,9.

A porcentagem de gordura abdominal declinou $(\mathrm{P}<0,05)$ com a redução da relação EM: PB ou maior conteúdo de proteína em relação à EM (Tabela 5), fato também observado por Silva et al. (2001), que notaram redução semelhante na gordura abdominal, à medida que a relação EM: PB diminuiu.

Na Tabela 6, são apresentados os efeitos do nível de EM e da relação EM:PB da ração sobre matéria seca e conteúdo de proteína e de lipídeos da carcaça das aves no período de 1 a 21 dias.
Houve interação $(\mathrm{P}<0,05)$ para o teor de matéria seca da carcaça, que cresceu quando a relação EM:PB passou de 125,0 para 151,5 em todos os níveis de EM (Tabela 6). Por outro lado, dentro da relação 125, os níveis de energia de 2.850 e 3.150 kcal de EM influenciaram maior porcentagem de MS na carcaça que o nível de $3.000(\mathrm{P}<0,05)$, enquanto, na relação 151,5, o maior conteúdo de MS foi observado com 3.150 e o menor com $3.000(\mathrm{P}<0,05)$.

Foi observada relação inversa entre o conteúdo de proteína da carcaça (diminuiu) e o teor de lipídeo (cresceu), quando a relação EM: PB foi elevada em todos os níveis de $\mathrm{EM}(\mathrm{P}<0,05)$. A explicação para este resultado foi o aumento da ingestão de ração, para atender às demandas protéicas, proporcionando consumo de energia acima das necessidades das aves, desviado para deposição de lipídios na carcaça. Kessler \& Brugalli (1999) e Silva et al. (2001) observaram máxima deposição de proteína e mínima de gordura corporal com baixas relações EM:PB na ração.

Dentro das relações 125,0, maior teor de proteína na carcaça foi encontrado na densidade energética de 3.000 em relação a 3.150, mas não houve diferença do nível de $2.850 \mathrm{kcal}$ de EM, ao passo que, dentro da relação 136,9 o maior teor de lipídio na carcaça foi detectado no nível de 2.850 kcal de EM, em comparação com o nível de 3.000 kcal. Dentro da relação 151,5, o conteúdo de proteína da carcaça não foi afetado pelos níveis de EM $(\mathrm{P}>0,05)$.

Tabela 5 - Efeito da energia e da relação EM: PB nas rações sobre a gordura abdominal (GAB) em frangos de corte de 1 a 21 dias de idade

Table 5 - Effect of energy and ME: CP ratio on abdominal fat $(A F)$ in broiler male chicks from 1 to 21 days old

\begin{tabular}{lcccc}
\hline EM: PB & \multicolumn{3}{c}{$\begin{array}{c}\text { GAB }(\%) \\
\text { ME:CP }\end{array}$} & \multicolumn{3}{c}{$\begin{array}{c}\text { Média } \\
\text { Mean }\end{array}$} \\
\cline { 2 - 4 } & 2.850 & 3.000 & 3.150 & \\
\hline 125,0 & 1,11 & 1,25 & 1,27 & $1,21^{\mathrm{B}}$ \\
136,9 & 1,22 & 1,38 & 1,32 & $1,30^{\mathrm{B}}$ \\
151,5 & 1,48 & 1,62 & 1,83 & $1,64^{\mathrm{A}}$ \\
Média & $1,27^{\mathrm{b}}$ & $1,41^{\mathrm{ab}}$ & $1,47^{\mathrm{a}}$ & \\
Mean & \multicolumn{3}{c}{15,00} \\
CV $(\%)$ & \multicolumn{3}{c}{} \\
\hline
\end{tabular}

a,b Letras minúsculas comparam médias de energia como efeito principal pelo teste SNK $(P<0,05)$.

Small letters comparing means of energy as principal effect by SNK test $(P<.05)$.

A,B Letras maiúsculas comparam médias das relações EM:PB como efeito principal pelo teste SNK $(P<0,05)$.

Capital letters comparing means of $M E: C P$ ratio as principal effect by SNK test $(P<.05)$. 
Tabela 6 - Efeito da energia e da relação EM:PB nas rações sobre gordura abdominal (GAB), matéria seca (MS), proteína (PC) e lipídio da carcaça (LC) de frangos de corte de 1 a 21 dias de idade

Table 6 - Effect of energy and ME:CP ratio on abdominal fat (AF), dry matter (DM), carcass protein (CP) an carcass lipid (CL) yields of broiler male chicks from 1 to 21 days of age

\begin{tabular}{|c|c|c|c|c|c|c|c|c|c|}
\hline \multirow[t]{2}{*}{$\begin{array}{l}\mathrm{EM}: \mathrm{PB} \\
M E: C P\end{array}$} & \multicolumn{3}{|c|}{$\begin{array}{c}\text { MS (\%) } \\
D M\end{array}$} & \multicolumn{3}{|c|}{$\begin{array}{c}\mathrm{PC}(\%) \\
C P\end{array}$} & \multicolumn{3}{|c|}{$\begin{array}{c}\mathrm{LC}(\%) \\
C L\end{array}$} \\
\hline & 2.850 & 3.000 & 3.150 & 2.850 & 3.000 & 3.150 & 2.850 & 3.000 & 3.150 \\
\hline 125,0 & $27,10^{\mathrm{aB}}$ & $25,92^{\mathrm{bB}}$ & $26,82^{\text {ав }}$ & $57,75^{\mathrm{abA}}$ & $58,41^{\text {aA }}$ & $55,17^{\mathrm{bA}}$ & $32,82^{\mathrm{aB}}$ & $31,66^{\mathrm{aC}}$ & $33,23^{\mathrm{aB}}$ \\
\hline 136,9 & $26,69^{\mathrm{aB}}$ & $27,63^{\mathrm{aA}}$ & $27,09^{\text {ав }}$ & $58,58^{\mathrm{aA}}$ & $54,37^{\mathrm{bB}}$ & $56,38^{\mathrm{abA}}$ & $30,63^{\text {ьв }}$ & $35,74^{\mathrm{aB}}$ & $34,98^{\mathrm{aB}}$ \\
\hline 151,5 & $28,99^{\mathrm{bA}}$ & $\begin{array}{c}27,60^{\mathrm{cA}} \\
8,56\end{array}$ & $30,20^{\mathrm{aA}}$ & $52,56^{\mathrm{aB}}$ & $\begin{array}{c}53,94^{\mathrm{aB}} \\
2,79\end{array}$ & $51,56^{\mathrm{aB}}$ & $38,31^{\mathrm{aA}}$ & $\begin{array}{c}38,45^{\mathrm{aA}} \\
4,30\end{array}$ & $39,81^{\text {aA }}$ \\
\hline
\end{tabular}

a,b,c Letras minúsculas comparam as médias de energia dentro de cada relação EM:PB pelo teste $S N K(P<0,05)$.

$a, b, c$ Small letters comparing means of energy within each ratio by SNK test $(P<.05)$.

$A, B$ Letras maiúsculas comparam as médias das relações $E M: P B$ dentro de cada valor de EM pelo teste de $S N K(P<0,05)$.

$A, B$ Capital letters comparing means of ME:CP ratio within of different ME values by $S N K$ test $(P<.05)$.

\section{Conclusões}

Rações formuladas com relação EM: PB de 136,9 (21,91\% PB) e 3.000 kcal de EM atendem adequadamente às exigências de frangos de corte para ótimo crescimento, no período de 1 a 21 dias de idade.

\section{Literatura Citada}

BATAL, A.B.; PARSONS, CM. Effects of age on nutrient digestibility in chicks fed different diets. Poultry Science, v. 81, p.400-407, 2002.

BARTOV, I.; PLAVNIK, I. Moderate excess of dietary protein increases breast meat yield of broiler chicks. Poultry Science, v.77, p.680-688, 1998.

BENICIO, L.A.S. Estudo da influência de linhagens e de níveis nutricionais sobre desempenho, rendimento de carcaça e avaliação econômica em frangos de corte. Viçosa, MG: Universidade Federal de Viçosa, 1995. 159p. Tese (Doutorado em Zootecnia) - Universidade Federal de Viçosa, 1995.

BERTECHINI, A.G.; ROSTAGNO, H.S.; SOARES, P.R. et al. Efeitos de programas de alimentação e níveis de energia da ração sobre o desempenho e a carcaça de frangos de corte. Revista Brasileira de Zootecnia, v.20, p.267-280. 1991.

HOLSHEIMER, J.P.; RUENSKI, E.W. Effect on performance, carcass composition, yield, and financial return of dietary energy and lysine levels in starter and finisher diets fed to broilers. Poultry Science, v.72, p.806-815, 1993.

EMMANS, G.C. Problems in modeling the growth of poultry. World's Poultry Science Journal, v.51, p.77-89, 1995.

JACKSON, S.; SUMMERS, J.D.; LEESON, S. Effect of dietary protein and energy on broiler carcass composition and efficiency of nutrient utilization. Poultry Science, v.61, p.2224-2231, 1982.

KESSLER, A.M.; BRUGALLI, I. Recentes avanços do efeito da nutrição no crescimento específico de componentes da carcaça de frangos de corte. In: SIMPÓSIO INTERNACIONAL SOBRE TECNOLOGIA DE PROCESSAMENTO E QUALIDADE DE CARNE DE AVES, 1999, Concórdia. Anais... Concórdia: EMBRAPA, 1999. p.1-19.
LESSON, S. Nutrição e qualidade da carcaça de frangos de corte. In: CONFERÊNCIA APINCO DE CIÊNCIA E TECNOLOGIA AVÍCOLAS, 1995, Curitiba. Anais... Curitiba: FACTA, 1995. p.111-118.

LEESON, S.; SUMMERS, J.D. Feeding programs of broilers. In: LEESON, S.; SUMMERS, J.D. (Eds.) Commercial poultry nutrition. 3.ed. University Books, 1997. p.207-298.

MACLEOD, M.G.. Fat deposition and heat production as responses to surplus dietary energy in fowls given a wide range of metabolizable energy: protein ratios. British Poultry Science, v.32, p.1097-1108, 1991.

MAIORKA, A.; LECZNIESK, J.; BARTELS, H.A. et al. Efeito do nível energético da ração sobre o desempenho de frangos de corte de 1 a 7,7 a 14 e 14 a 21 dias de idade. In: CONFERÊNCIA APINCO DE CIÊNCIA E TECNOLOGIA AVÍCOLAS, 1997, São Paulo. Anais... São Paulo: FACTA, 1997. p.18.

PENZ, JR., A.M.; KESSLER, A.M.; BRUGALLI, I. Novos conceitos de energia para aves. In: SIMPÓSIO INTERNACIONAL SOBRE NUTRIÇÃO DE AVES, 1999, Campinas. Anais... Campinas: FACTA, 1999. p.1-24.

PESTI, G.M.; FLETCHER, D.L. The response of male broiler chickens to diets wirn various protein and energy contents during the growing phase. British Poultry Science, v.24, p.91-99, 1993.

ROSTAGNO, H.S.; BARBARINO JR., P.; BARBOZA, W.A. Níveis nutricionais utilizados nas rações pela indústria avícola. In: SIMPÓSIO INTERNACIONAL SOBRE EXIGÊNCIAS NUTRICIONAIS DE AVES E SUÍNOS, 1996, Viçosa, MG. Anais... Viçosa, MG: Universidade Federal de Viçosa, 1996, p.361-388.

ROSEBROUGH, R.W.; MITCHEL, A.D.; VON VLECK, M.F. et al. Protein and energy relation in the broilers chicken. British Journal Nutrition, v.69, p.515-523, 1990.

ROUND, J.S.K. Influence of feed on carcass composition and quality. World's Poultry Science Journal, v.48, p.69-71, 1992.

SCOTT, M.L.; NESHEIN, M.C.; YOUNG, R.J. Nutrition of the chicken. Ithaca: 1982. 555p.

SILVA, J.H.V.; ALBINO, L.F.T.; NASCIMENTO, A.H. Níveis de energia e relações energia: proteína para frangos de corte de 22 a 42 dias de idade. Revista Brasileira de Zootecnia, v.30, p.1791-1800, 2001.

R. Bras. Zootec., v.33, n.4, p.911-918, 2004 
SILVA, J.H.V.; ALBINO, L.F.T.; NASCIMENTO, A.H. Estimativas da composição anatômica da carcaça de frangos de corte com base no nível de proteína da ração e peso da carcaça. Revista Brasileira de Zootecnia, v.32, n.2, p.344-352, 2003.

STRINGHINI, J.H.; ANDRADE, M.L.; ROSA, R.M. et al. Efeito da relação energia: proteína na ração de primeira semana sobre o desempenho de frangos de corte. In: CONFERÊNCIA APINCO DE CIÊNCIA E TECNOLOGIA AVÍCOLAS 2001, CAMPINAS. Anais... Campinas: FACTA, 2001. p.36.

UNIVERSIDADE FEDERAL DE VIÇOSA - UFV. SAEG (Sistema de análises estatísticas e genéticas). Versão 7.1. Viçosa, MG, 1997. 150p. (Manual do usuário).
ZANUSSO, J.T. Níveis de energia metabolizável para frangos de corte de 1 a 21 dias de idade mantidos em ambiente de conforto e estresse térmico. Viçosa, MG: Universidade Federal de Viçosa, 1998. 64p. Dissertação (Mestrado em Zootecnia) - Universidade Federal de Viçosa, 1998.

Recebido em: 22/07/02

Aceito em: 02/10/03 